\title{
An Introduction to the Grounded Theory Approach in Social Research
}

\author{
Venkat Pulla \\ Social Work Programme, Australian Catholic University, Australia
}

\begin{abstract}
This paper discusses Grounded theory, which is one of the newer methodologies becoming popular with social researchers since its evolution in the late 1960's. The paper discusses the principles and processes of Grounded theory and then explores the nature of codes, coding process and the concept of saturation. The paper then goes on to discuss the pros and cons, arguments for and against the use of Grounded theory methodology for social research and explores the applicability of this methodology in producing sound theoretical basis for practice. Select narratives from the author's recent studies are utilised to explain the processes of grounded theory methodology.
\end{abstract}

Keywords Grounded Theory, Qualitative Research, Data Analysis, Inductive Research

\section{Introduction}

One of the key concerns of social research is to examine humans and their behaviors alongside baffling philosophical questions in quest for truth, knowledge, values and being, and how these features govern human behaviors and activities (Somekh, Burman, Delamont, Meyer, Payne and Thorpe, 2011; Pulla, 2014a). In other words, central to social research is to determine "who we are as people, why we act the way we do and what may be some of the outcomes of these actions and behaviours with regards to others in our society and environment and the systems surrounding all of us" (Pulla, 2014a: 15). Thus, "social researchers seek to identify order and regularity in the complexity of social life; they try to make sense of it" (Ragin 1994: 31). Social research includes variables such as time and space that our interactions occupy. Differing from the stringent methods of scientific research with its clear parameters and measurability, social research allows for interpretive analysis subsuming the varied ways as to how people think, feel and act. This is not to say that social scientists do not make measurement, they do. With careful collection of data and subsequent interpretation of these data, findings provide considered answers to questions about human behavior, people, communities and societies. I believe that Grounded Theory is a research method that seeks to develop theory that is grounded in data, collected systematically and analyzed. It is imperative in the method that a continuous interplay between data collection and analysis occurs throughout the research process.

Despite being in vogue for the last fifty years or less, Grounded Theory has become 'the discovery of theory from data - systematically obtained and analysed in social research' (Glaser \& Strauss, 1967:1). The methodological thrust of grounded theory is toward the development of theory, without any particular commitment to specific kinds of data, lines of research, or theoretical interests. Rather, it is a form of executing qualitative analysis that includes a number of distinct features, and uses a coding paradigm to ensure conceptual development and density (Strauss, 1987).

The first work in the new tradition of grounded theory was carried out with dying patients and resulted in a publication of Awareness of Dying (1965) by Glaser and Strauss. Subsequently, they released a methodology book titled Discovery of Grounded Theory (1967). Both these are seminal works that have allowed for Grounded theory to grow over the last five decades. Thus, a grounded theory is one which has developed from the use of Grounded Theory methodology, as was intended by the theory developers who made clear delineation between the Grounded Theory Method and the resultant theory (Bryant and Charmaz, 2007), although for the purpose of this paper, it is suggested that Grounded Theory refers to both the process or methodology and the resultant theory. This in turn allows to viewing Grounded Theory as a theory generating research methodology, even beyond the context of this paper that allows for the incorporation of scientific objectivity on one hand and the meticulousness into traditional subjective qualitative methodologies on the other to allow for both credibility and validity in research outcomes (Hennink, Hutter and Bailey, 2011). With the use of Grounded Theory, one can see then, the importance of maintaining traditional ISSN: 2332-6840 (Online) 2332-6832 (Print) Copyright (C) 2016 by authors, all rights reserved. Authors agree that this article remains permanently open access under the terms of the Creative Commons Attribution License 4.0 International License 
scientific precision for validity coupled with considered elucidation of perhaps not so readily measurable aspects of human life, thoughts, feelings, behaviors and interactions, and the meanings that people place on their life experiences.

It is expected that as a general rule, researchers that deploy grounded theory approach make sure that they have no preconceived theoretical ideas before embarking on their research project. This does not mean that one should ignore the review of literature. The intention clearly is to make sure that researchers are not constrained by literature when coding. Researchers clearly avail the opportunity not to impose concepts on the data, instead wait for the concepts to emerge from the data. In other words, the research does not begin with a theory, the theory is the outcome. It is a set of grounded concepts integrated around a central theme to form a theoretical framework that explains how and why persons, organisations, communities or nations experience and respond to events, challenges or problematic situations (Corbin and Holt, 2011).

The structure of the article is as follows: It begins with how to code in Grounded Theory research. It then discusses the principles and processes of Grounded Theory. The final section discusses its implications of using Grounded Theory.

\section{Coding in Grounded Theory Research}

Coding is an important phase in Grounded Theory Research. 'A code in qualitative inquiry is most often a word or short phrase that symbolically assigns a summative, salient, essence-capturing, and / or evocative attribute for a portion of language-based or visual data' ( Saldhana, 2012: 1-31). The following example is about a code generated from the description given by a research participant

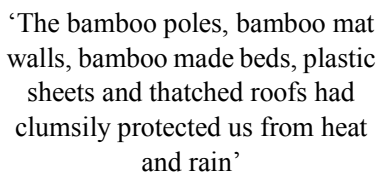

Descriptive code Housing

The following illustrations will assist in better understanding. In a recent study, the author and his colleague were trying to understand the sense of 'identity' and or 'belonging' of the Lhotsampa people of Bhutan who faced forced eviction from the land of Shangri-La (Pulla, 2016; also, Bhattacharyya, 2016, forthcoming). The study was researching intergenerational perceptions and the precipitating factors behind those perceptions about home country and settlement in a third country. The journey for this research was in grounded theory and thereby, had no preconceived logically deduced hypothesis, but codes were constructed as we moved on. Indeed, the sampling was aimed towards theory construction rather than population representativeness. However, limited literature was reviewed after developing our independent analysis (Charmaz, 2009). As we were learning from the data, our research participants also made sense of their experiences. The data were coded on the basis of the bits of information that existed beyond the data such as through ethnography of the Lhotsampas that came through in the literature review. Our research, as a result of 'intensive interviews' allowed us as interviewers to

- Go beneath the surface of the described experience(s)

- Stop to explore a statement or topic

- Come back to an earlier point

- Validate the participant's humanity, perspective or action (Charmaz, 2009: 26)

Interviews are contextual and remain negotiated that allow participants to recount their concerns without interruption. 'That is interesting, tell me more about it' is an approximate sentence after a nod that creates an ambience for new information to emerge from research participants- the result is a construction or a reconstruction of the reality (Charmaz, 2009). Interview stories do not reproduce prior realities (Murphy \& Dingwall, 2003; Silverman, 2000). There is a clear difference between an intensive interview process and an ordinary disclosure in everyday life. Even research participants have clear opportunities to reflect, grow and receive their light bulb movements and feel rewarded.

'Ram Rani Dahal narrated that her 18 years of refugee camp life experiences had been painful not having enough to purchase good food and clothing; fear of accidental fires, rain and flooding. The bamboo poles, bamboo mat walls, bamboo made beds, plastic sheets and thatched roofs had clumsily protected us from heat and rain. We made several attempts to repatriate to Bhutan our country of origin but failed' but biggest of all always haunted by the identity crisis- where do I belong?'

What do we learn from the above narrative? Identity questions were the research questions. Hence, logically main codes in this research. But new melancholic information that relates to 18 years of existence in the camps comes to surface. Although, we had knowledge that the Lhotsampas have been living in camps, but were not significant to us in the original research questions around the question of their 'identity' and initially we almost ignored this research participants' valid information. 'A researcher has a topic to pursue. Research participants have problems to solve, goals to pursue and actions to perform and they hold assumptions, ideas and feelings' (Charmaz, 2006: 33). Therefore, the research questions and mode of enquiry in grounded theory privilege a researcher to shape the subsequent data and analysis. Moreover, it allows the researcher to reshape research questions and focus or change the direction of the enquiry.

Unlike other qualitative methodologies, Grounded Theory does not test questions with a theory; it analyses data to produce a theory that answers those questions. Of importance and worthy of note, is that whilst Grounded theory is a theory producing method, the antithesis of other methodologies which begin with a theoretical underpinning, can incorporate general underlying beliefs or values system. It is such underlying beliefs that influence the questions that 
the researchers ask and the structure that the research takes. It is important then to acknowledge these beliefs and values at the beginning.

Here, the previous illustration from the Lhotsampa research is revisited. The researchers were aware that the children of the Bhutanese refugees, born in Nepal in the last two decades did not have any legal identities- neither they were Nepalese nor Bhutanese, which by itself is an issue for them. The study was attempting to understand the intergenerational perceptions around their identity but the participants of research led us into the precipitating factors behind their decisions to leave Nepal and allowed us to understand their perceptions about home country and settlement in a third country. We learned about their eagerness to a futuristic resettlement in a third country possibly was closely linked to their perceived social status in Nepal while they continue to languish in the camps in Eastern Nepal. When we heard a young participant say the following, we began to realize that we have new codes to add and new orientation in theory to explain:

'I know nothing of Bhutan and have nothing to be called as mine in Bhutan. The most influential factor for my decision regarding resettlement is the fact that I don't want to live hard non-existent life like my parents and grandparents here in Nepal camps. I want to be regarded and respected as 'somebody', I will build my identity in new place, a new identity'

The above illustration from our research confirms that as researchers we were not focused on testing hypotheses taken from existing theoretical frameworks, rather open to developing a new 'theory' grounded in empirical data collected from the field. As such, the data of the young participant above has deliberately privileged our theoretical orientations.

Social research quite logically focus on a certain amount of literature review even in all qualitative research designs and often mentors suggest to us that it is through literature review that we identify gaps and it is in those gaps there are myriad opportunities for research. But early on, Glaser and Strauss (1967) explicitly advised against conducting a literature review in the substantive area of research at an early stage of the research process: '[a]n effective strategy is, at first, literally to ignore the literature of theory and fact on the area under study' (1967: 37). The idea I presume emerges from the notion not to be stormed by extant theoretical constructs and hypotheses but to allow exposure to naturally emerging categories from the data. The argument appears reasonable and as such sustained as ploughing early may be a 'potentially stifling process' (Dunne, 2011: 114). Unlike most strategies of inquiry, grounded theory demands that data collection and analysis occur concurrently, rather than in a linear sequence affording a 'dynamic interplay of data collection and analysis' Payne (2007: 68). Having said this, I do not advocate a puritanical approach to grounded theory based research. To me, a certain prior review of the area is fine as long as it does not consummate the researcher and the researcher is sincerely open to the data to lead her/him into new pastures for theory development. I also do not advocate a grounded theory approach to a novice in social research, but certainly agree with Charmaz's suggestion that delaying the literature review can help 'to avoid importing preconceived ideas and imposing them on your work' (2006: 165) rather encourages you to articulate your ideas.

\section{Principles and Processes of Grounded Theory}

Grounded theory in reality provides a process for developing theory from research and is underpinned by the following principles:

- Data analysis is non- linear and revolves in a circular process, which may involve the researcher repeating or overlapping which allows for a depth in the research data.

- Interviews are transcribed verbatim, allowing for an emic perception of the data, an understanding and interpretation of the interviewees' own perspective.

- Data collection and analysis are interlinked, thus allowing for the circular process, which allows for not only analysis but also effectively, reanalysis and reinterpretation ensuring valid end product.

- Inductive analysis is used which does not make assumptions and allows the data to narrate the story.

- Continuing comparison is used to interpret data and evaluate concepts that arise, then further collect and interpret data, and so on in a circular motion.

- Analytic memo writing is used to track the theory development process.

- Analysis involves more than description and involves explanation and eventually theory (Hennink, Hutter and Bailey, 2011).

With the above principles at the core of the methodology, we then must discuss the process of Grounded theory research. With a starting point and outcomes that differ from other methods of qualitative research, Grounded theory must inevitably have process(es) that distinguish it from other qualitative research methodologies. As such, Grounded theory has a set of tasks that are repeated throughout the research process to produce the cyclical nature of Grounded theory with the result of producing data that is thoroughly analyzed. Overall, while it presents guidelines for collecting and interpreting data for the production of theory, these guidelines remain flexible and intended to be so to allow the researcher to react to the data as it is collected and analyzed (Hennink, Hutter and Bailey, 2011). The set of original tools intended by Glaser and Strauss for Grounded theory methodology are the following:

- Verbatim transcripts

- Anonymity 
- Development of codes

- Definition of codes

- Coding of data

- Describe data

- Compare data

- Categorise data

- Conceptualise

- Theory development

(Hennink, Hutter and Bailey, 2011)

In keeping with the flexibility and circular nature of Grounded theory methodology, these steps may be followed in order, or not and also reapplied as often as is necessary until the theory is produced. The key factor is the data, the collection with acknowledgment of researcher beliefs and values, the analysis and interpretation of the data and the theory that arises from the data. In this way, we can see the evolution of theory about themes of social research that is discovered from within the data itself rather than imposed by ideas and values and beliefs of a researcher who is aiming to fit data to a research question. One could argue here quite validly, that Grounded theory presents perhaps the best means of discovering truthful theory from the real source of knowledge.

\section{Data, Codes and Coding}

The process of Grounded theory begins with and is inextricably linked to data collection. This data takes the form of verbatim interviews (Hennink, Hutter and Bailey, 2011). The researcher must ensure that the interview is transcribed exactly as recorded. This is crucial for Grounded theory where the result, the theory, is derived not from concepts or ideas held by the researcher, but evolves from the ongoing, inductive motion of data collection and analysis (Oliver, 2012). Unlike other methodologies, the analysis can and should begin as soon as data is collected (Oliver, 2012). Upon receipt, the data is coded (Oliver, 2012) and every line is coded in detail in a process known as microanalysis (Hennink, Hutter and Bailey, 2011). Each interview transcript is coded in this way with microanalysis more beneficial at the beginning of the research to develop a list of concepts for further analysis. Corbin and Strauss (2008) describe this process as the means to break open the data to ensure all possible meanings are disclosed (Oliver, 2012). The whole process is qualitative and coding then suggests naming segments of data with a label that simultaneously categorizes, summarizes and accounts for each piece of data. In the inset below is an example of narrative on the right side and the possible codes that we carried in the study example:

Box 1 Grounded Theory Coding Example

Participants raise many open ended questions they raise and have no answers.

For many refugees resettlement is not an option.

Leaving forever their national identity.

Shifting to an alien land is traumatic.

The senior population requires a separate analysis.

Their reluctance and agony and their dilemmas.

They want to be with their family. They do not want to go to foreign lands.

A 'No choice' - choice of either languishing in Nepal camps or moving to another country.

Ageing; Age related degenerative health

Increased dependency on children to care

Suffering in camps depicted as humiliation and indignity and degrading and dividing people

Dissatisfaction with the approach of resettlement

Questions on Resettlement policy
Three Narratives:

'I had always dreamed of returning home someday. We fought, we hoped. We patiently waited. And now I am confused like I never was in my life' (pauses a while, and continues to talk) 'I am 64 years old. How I would describe how I feel about my current state of my mind regarding going to America? To me America is a compulsion, the last resort. "I don't know what else I can do for my children. I don't want them to go through the same fate as I did. I lost my wife in the fight and now I can't sacrifice their future for me. I will go with them for their better life'. His voice fades and breaks.

A woman participant aged 60 said 'A few weeks back, there was a huge discussion at my house regarding applying for resettlement. I resisted for years and now I am awaiting my name in the list. My cousins and sister-in-law are all in America. They are happy there and they have been asking me to come as well. I don't know what to do now when my sons have already applied for resettlement. I am old and in no way can support myself now. I have to be with my family. And for that I have to go with them. I am in the biggest dilemma of my life. I want to return home ( Bhutan). But do I have a choice?

A third participant said 'The UNHCR advocates for the protection of human rights of the refugees like us, or that's what I heard. But I don't feel like being protected. I feel like I am the dirt on a marble floor waiting to be swept away. These ideas of resettlement are dividing us. A deep hole is being dug between us. Our unity of refugees is being degrading in many ways. My identity is Bhutanese I am against the idea of forever leaving Bhutan. Although I feel that returning Bhutan is a distant dream for me and others like me. I still hold on to my tiny bit of hope left after years of struggle. A home is a home. But the family is everything. It is breaking us within to decide on what to choose for our future. I wish the international community could understand that. I wish we didn't have to choose between our hearts and our souls' 
The logic of initial coding allows us to the questions:

- What are the data suggesting? Or "pronouncing" (Charmaz, 2007: 47)

- From whose point of view?

- What theoretical categories are emerging from the data under study?

Thus initial coding sticks close to data and goes beyond any pre-existing categories in the data. The attempt is to code with words that reflect actions. This certainly is not to suggest an empty head but an open mind.

\section{Memo Writing}

Journey into research is expected to move on to the next stage of what is called memo writing. Memos are written throughout the research as a way to capture what the researcher is thinking about the data, to track concepts for further explanation and as a means of further analysis of the coded data (Hennink, Hutter and Bailey, 2011, Oliver, 2012). Eventually the memos can become data in and of themselves (Oliver, 2012).

From this data collection and concurrent analysis, a process known as theoretical sampling is utilized to source new data with which the emerging concepts can be further explored (Oliver, 2012). It is this cyclical motion of data collection, immediate analysis and further collection that forms the very basis of Grounded theory. It is this process that makes Grounded theory unique in the vast array of possible research methodologies for social research. Another term used in Grounded Theory is called saturation by which it is suggested that the research process has ceased to yield no more new data (Morse, 2007). When the researcher feels that no new information is to be gained regarding a particular concept from the collected data, analysis can move forward to the next step and sampling ceases. The researcher knows when saturation has been reached when all the respective data has been analysed, the researcher understands all that has been identified and there is consistency across the many forms (Morse, 2007).

\section{Pros and Cons of Grounded Theory}

Inevitably, Grounded theory has both admirers and detractors. It is the stance of this paper that Grounded theory presents an appropriate methodology for social research as well as a valid and practicable means of developing theory but of course, as well it should be, it is the nature of the social researcher to explore these arguments. To consider the detractors first it is necessary to explore the following criticisms of Grounded theory - it is a lengthy, time consuming and often ambiguous process and that it places too much emphasis on the source of knowledge resting in social constructions (Corbin and Holt, 2011).

It requires intensive interviews, textual analysis, remains a fluid, interactive and open-ended process while the researcher sits through transcribing relentlessly written memos, analyzed and coded, memos re-written and then coded and analyzed, and all until saturation is reached. Grounded theory perhaps does not lend itself to a quick sampling of a small number of research participants. However, it is within this criticism that benefit may also be seen. Grounded theory being a thorough exploration, whilst time consuming, may also be considered more meaningful due to the lengthy process. For theory that is developed from its embedded place with the data, surely uncovering this theory should involve a process that is comprehensive and exhaustive and involves painstaking analysis of collected data. To utilize an inductive process with interpretive and revelatory analytical progressions to arrive at sound theoretical concepts is surely of benefit more so than detriment. Thus, it is from this criticism that we may indeed also come to view a major benefit. Grounded theory is inductive and begins with no preconceived ideas, it utilizes meticulous exploration of precisely transcribed data, coded comprehensively to the point of saturation to arrive at sound and valid conceptual ideas upon which theory can be grounded. This must take time, it must inherently be a lengthy process but instead of framing this time consumption as negative, perhaps it is the very essence of why Grounded theory is so applicable for social research.

The other critique of Grounded theory that bears some exploration is that when compared to other methodologies for empirical research, it may be that Grounded theory places too much emphasis on knowledge being based on what may be deemed social constructions (Oliver, 2012). Unlike research in the natural sciences, which used a rationalistic, structured approach to determine how the natural world works, social scientists seek to determine not only how people behave but also how they interact and think, and make meaning from their experiences and contexts (Oliver, 2012). Once again then, we can see how a critique can be instead utilised to support an argument for Grounded theory rather than dissuade. People do indeed interact with their environments, and make individual meaning from their experiences, and perceive environmental stimuli in unique interpretations, which inevitably affect reactions and then ultimately behaviour. Therefore, to argue that Grounded theory places much emphasis on knowledge that is collected from people and then analyzed to explore these individual interpretations is in reality an argument against the concept of social research in entirety. One could make counter argument that the very purpose of social research is to gather knowledge from the interaction of people with their contextual environs, and thus, the use of Grounded theory as a methodology for such is indeed appropriate.

In support of Grounded theory as a meaningful and purposeful methodology for social research are the arguments that Grounded theory meets the wide range of philosophical and ideological requirements of researchers from a number of disciplines. Grounded theory can be used by researchers who hold any number of underlying beliefs 
and values and may be coupled with numerous theoretical underpinnings but as it is not guided by any theoretical base giving the Grounded theory process great flexibility (Evans, 2013). As noted earlier in this paper, it is vital for the researcher to acknowledge underlying ideologies and beliefs due to the impact they can have on the structure of the research and the way in which the researcher conducts the research. So with some self-awareness, reflective practice and professional research ethics, Grounded theory can prove to be a valid and effective research methodology for many subjects and across numerous disciplines.

The most convincing point in favor of Grounded theory as a means of social research is that Grounded theory by its very nature produces theory that is grounded in the data, which it has explored. Thus, the nature of Grounded theory makes it applicable and valid as a means of generating theory, which can then be used for work with the very people from whom the data was collected in the first place. It appears quite apparent that Grounded theory should be utilised for those researchers who are aiming to discover and develop theories for practice in which people are the core business.

\section{Implications for the Social Researcher}

For the social researcher, the implications of using Grounded theory are important. For the student or a budding researcher, it may be necessary to garner some support from mentors or colleagues due to the vast differences between Grounded theory and other research methodologies for social research.

Ethics committee may also require open and honest discussion of the validity of the Grounded theory methodology, which of course has no theoretical underpinning at the beginning and may well seem, to the committee member with little experience of Grounded theory, a dangerous and unguided delving into the human behaviour. The researcher must in this case present a valid reason for using grounded theory and may need to provide some more information regarding the methodology and also the process and procedures it will entail.

The Grounded theory methodology requires a question much broader than other qualitative methods, which may be a difficult concept for experienced researchers. It is a point worth noting however because the nature of this methodology is to refine the question throughout the process to the point where theory can be developed rather than beginning with a theory and testing a narrowly defined hypothesis.

The circular nature of data collection and analysis for Grounded theory may well require second interviews for clarification from the same participant. This may be important to note at the first interview and be incorporated into the consent and information packages for ethical practice.

\section{Conclusion}

The use of Grounded theory as a qualitative research methodology, although not by any means a methodology with as long a history as others is a most appropriate methodology for social research. With a process that involves data collection and concurrent analysis in a cyclical motion to produce concepts from which a theory will evolve, it produces an end result that is embedded in the data from which it has been extricated. This is perhaps what makes grounded theory most appropriate for social research, that the theory, which is not assumed by the researcher at the beginning, evolves out of data given by a sample of people and is then refined for use for work with those same people.

\section{REFERENCES}

Bhattacharyya, R. (2017, forthcoming). Book Review- Venkat Pulla (2016, ed.), The Lhotsampa People of Bhutan: Resilience and Survival, New York, Palgrave Macmillan, ix+184pp., £68.00, \$95.00, Hardback 9781137557216, Journal South Asia Research, 37 (1).

Bryant, A. and Charmaz, K. (2007). Grounded theory in historical perspective: An epistemological account. pp, 29-57. In A. Bryant and K. Charmaz (Eds.). The Sage Handbook of Grounded Theory. London: Sage Publications.

Corbin, J. and Holt, N.L. (2011). Grounded theory. pp, 113-120. In, B. Somekh and C. Lewin. (Eds.). Theory and Methods in Social Research. ( $2^{\text {nd }}$ ed.). London: Sage Publications.

Dunne, C. (2011). The place of the literature review in grounded theory research. International Journal of Social Research Methodology. 14 (2), March 2011, 111-124

Evans, G. (2013). A Novice Researcher's First Walk Through the Maze of Grounded Theory: Rationalization for Classical Grounded Theory. The Grounded Theory Review. 12(1), 37-55.

Glaser, Barney G. and Strauss, Anselm L. (1965). Awareness of Dying. Chicago: Aldine.

Glaser, Barney G. and Strauss, Anselm L. (1967). The Discovery of Grounded Theory: Strategies for Qualitative Research. Chicago: Aldine.

Hennink, M., Hutter, I. and Bailey, A. (2011). Qualitative Research Methods. London; Sage Publications.

Morse, J. (2007). Sampling in grounded theory. pp. 229-244. In A. Bryant and K. Charmaz (Eds.). The Sage Handbook of Grounded Theory. London: Sage Publications.

Oliver, C. (2012). Critical realist grounded theory: A new approach for social work research. British Journal of Social Work. 42, 371-387.

Payne, S. (2007). Grounded theory. In E. Lyons \& A. Coyle (Eds.), Analysing Qualitative Data in Psychology (pp. 65-86). London: Sage. 
Vol.4. No.4 September, 2016, pp. 75-81

Pulla, V. (2016, ed.), The Lhotsampa People of Bhutan: Resilience and Survival, New York, Palgrave Macmillan

Pulla, V. (2014a). Grounded Theory Approach in Social Research, Space and Culture, India, 2(3), 14-23, DOI: http://dx.doi.org/10.20896/saci.v2i3.93

Pulla, V. (2014b) The Lhotsampa studies (un published memos)
Ragin, C. (1994). Constructing Social Research, Thousand Oaks: Pine Forge Press

Saldhana, J. (2012). The Coding Manual for Qualitative Researchers, London, Sage Publications.

Somekh, B., Burman, E., Delamont, S., Meyer, J., Payne, M. and Thorpe, R. (2011). Research in the social sciences. pp, 2-16. . In, B. Somekh and C. Lewin. (Eds.). Theory and methods in social research. (2nd ed.). London: Sage Publications. 